\title{
Health Behavior Regarding Liver Flukes among Rural People in Nakhon Ratchasima, Thailand
}

\author{
Sirinapa Painsing ${ }^{1}$,Anan Sripong ${ }^{1}$, Orramon Vensontia ${ }^{1}$, Prasit Pengsaa ${ }^{2}$, Pontip \\ Kompor $^{2}$, Nusorn Kootanavanichapong ${ }^{3}$, Soraya J Kaewpitoon ${ }^{4,5,6}$, Natthawut \\ Kaewpitoon ${ }^{2,3,4 *}$
}

\begin{abstract}
Opisthorchiasis is a health problem in Thailand particularly in northeast and north regions where have been reported the highest of cholangiocarcinoma. Active surveillance is required, therefore a cross-sectional surveyed was conducted in Nong Bunnak sub-district of Nakhon Ratchasima province, Thailand. A total of 367 participants were selected by multistage sampling from 5 villages located near natural water resources. Participants completed a predesigned questionnaire containing behavior questions regarding liver fluke disease, covering reliability and validity knowledge (Kuder-Richardon-20) $=\mathbf{0 . 8 0}$, attitude and practice (Cronbach's alpha coefficient $)=0.82$ and 0.79 , respectively. Descriptive statistics included frequencies, percentages, means, and standard deviations. The majority of the participants were female $(58.3 \%)$, age group between $21-30$ years old $(42.5 \%)$, with primary school education $(59.9 \%)$, occupation in agriculture $(38.1 \%)$, and married $(80.9 \%)$. They had past histories of raw fish consumption $(\mathbf{8 8 . 3 \%})$, stool examination $(\mathbf{1 . 4 \%})$, anti-parasite medication used $(4.6 \%)$. Heads of villages, village health volunteers, television, and village newstations were the main sources for disease information. Participants had a moderate level of behavior regarding liver fluke disease. The mean scored of knowledge regarding liver fluke life cycle, transmission, severities, treatment, prevention and control was $10.9(\mathrm{SD}=0.5)$, most of them had a moderate level, $95.1 \%$. The mean score for attitude regarding liver fluke prevention and control was $45.7(\mathrm{SD}=9.7)$, and for practice was $30.6(\mathrm{SD}=10.5)$. Participants had a moderate level of attitude and practice, $94.5 \%$ and 47.7 , respectively. This study indicates that health education is required in this community including stool examination for liver fluke as further active surveillance screening.
\end{abstract}

Keywords: Health behavior - liver fluke - nong bum mak district - Nakhon Ratchasima - Thailand

Asian Pac J Cancer Prev, 17 (4), 2111-2114

\section{Introduction}

Liver fluke caused by Opisthorchis viverrini, is a health problem in Thailand particularly in the northeast and north region (IARC, 1994; Kaewpitoon et al., 2008; Shin et al., 2010; Sripa et al., 2010; Sithithaworn et al., 2012; Wongsaroj et al., 2014; Kaewpitoon et al., 2015e). $O$. viverrini infection is the etiology of cholangiocarcinoma (CCA) (Thamavit et al., 1978; Kaewpitoon et al,. 2008; Sripa et al., 2007; Sripa et al., 2012 ). This CCA has been reported that Thailand is the highest incident of the world (Green et al., 1991). Mortality rate of CCA in Thailand was approximately $36.48 \%$. The mortality rate of CCA in Nakhon Ratchasima province, Thailand was ranked between 13.67-16.2 (Sripa et al., 2012). Current status of liver fluke infection in Thailand was a nationwide surveyed (Wongsaroj et al., 2014). The highest of prevalent was found in the northeast $(9.2 \%)$ and followed by the north region $(5.2 \%)$. In Nakhon Ratchasima province was surveyed. A total of 1,168 stool samples were obtained from 516 males and 652 females. Stool examination showed that $2.48 \%$ were infected with $O$. viverrini (Kaewpitoon et al., 2012). In addition, re-examination in Nakhon Ratchasima province has been reported and found that $O$. viverrini infection is still problem in rural communities (Kaewpitoon et al., 2016a; 2016c)

Previously studied indicated that knowledge, attitude, and practice related to liver fluke infection in rural communities (Kaewpitoon et al., 2007). Therefore, the active survey of health behavior is need required. This study aimed to investigate the knowledge, attitude, and practice regarding liver fluke. The result may useful for further study and planning of liver fluke prevention and control.

${ }^{I}$ Graduate Student, ${ }^{2}$ Program of Master of Public Health, ${ }^{3}$ Program of Bachelor of Public Health, Faculty of Public Health, Vongchavalitkul University, Nakhon Ratchasima, ${ }^{4}$ Parasitic Disease Research Unit, ${ }^{5}$ Suranaree University of Technology Hospital, ${ }^{6}$ School of Family Medicine and Community Medicine, Institute of Medicine, Suranaree University of Technology, Nakhon Ratchasima, Thailand *For correspondence: natthawut.k@hotmail.com 


\section{Materials and Methods}

A cross-sectional surveyed was conducted in Nong Bunnak sub-district, Nong Bun Mak districts of Nakhon Ratchasima province, Thailand. Nong Bunnak was created as a minor district on July 1, 1983 by separating the three Nong Bunnak, Saraphi and Thai Charoen sub-districts from Choc Chai District. It was officially upgraded to a full district on May 25, 1989. In 2003 the district was renamed from Non Bunnak to Nong Bun Mak. Neighboring districts are (from the east clockwise) Nong Ki district of Buriram province, Khon Buri, Chok Chai, and Chakkarat districts of Nakhon Ratchasima province. The district is subdivided into 9 sub-districts (Nong Bunnak, Saraphi, Thai Charoen, Nong Hua Raet, Laem Thong, Nong Takai, Lung Khwao, Nong Mai Phai, and Ban Mai districts), which are further subdivided into 104 villages. Nong Bunnak sub-district is located in Non Bun Mak district, which is approximately 10 kilometers far from district and 70 kilometers from Nakhon Ratchasima province. There are further subdivided into 17 villages, 2,798 household, which are covered 101.29 kilometer $^{2}$. Total of 10,388 populations is divided into 5,126 male and 5,262 female.

A total of 367 participants was included that calculated following Krejcie and Morgan (1970). Participants was multistage sampling from 5 villages where are located nearly natural water resources, included Ban Hua Tamnob, Ban Nong Bunnak, Ban Sawang Pattana, Ban Nonjan Pattana, and Ban Nong Rangka villages as 100, 80, 60, 51, and 76 participants, respectively. Participants were

Table 1. Demographic data of participants from Nong Bunnak sub-district, Nong Bun Mak district, Nakhon Ratchasima, Thailand

\begin{tabular}{|c|c|c|}
\hline Characteristics & No of participant & $\%$ \\
\hline \multicolumn{3}{|l|}{ Gender } \\
\hline Male & 153 & 41.7 \\
\hline Female & 214 & 58.3 \\
\hline \multicolumn{3}{|l|}{ Age (years old) } \\
\hline $15-20$ & 14 & 3.8 \\
\hline $21-30$ & 156 & 42.5 \\
\hline $31-40$ & 114 & 31.1 \\
\hline $41-50$ & 66 & 18.0 \\
\hline $51-60$ & 16 & 4.4 \\
\hline$>60$ & 1 & 0.3 \\
\hline \multicolumn{3}{|l|}{ Education } \\
\hline Uneducated & 10 & 2.7 \\
\hline Primary school & 220 & 59.9 \\
\hline Secondary school & 114 & 31.1 \\
\hline Diplomate & 15 & 4.1 \\
\hline Undergraduate & 8 & 2.2 \\
\hline \multicolumn{3}{|l|}{ Occupation } \\
\hline Employee & 132 & 36 \\
\hline Agriculture & 140 & 38.1 \\
\hline Own business & 63 & 17.2 \\
\hline Housewife & 25 & 6.8 \\
\hline Government officer & 7 & 1.9 \\
\hline \multicolumn{3}{|l|}{ Marital status } \\
\hline Single & 37 & 10.1 \\
\hline Married & 297 & 80.9 \\
\hline Divorced/separated & 33 & 9.0 \\
\hline
\end{tabular}

completed a predesigned questionnaire containing (1) demographic data; gender, age, education, agriculture, and marital status, (2) past histories with raw fish consumption, stool examination, and anti-parasites used, (3) perception of disease information, (4) knowledge; 15 questions with liver fluke transmission, opisthorchiasis, severity, sign and symptom, treatment, prevention and control, (5) attitude; 20 questions with prevention and control of liver fluke, and (6) practice; 15 questions with prevention and control of liver fluke. Reliability and validity of questionnaire was analyzed, knowledge (Kuder-Richardon-20 (Kuder and Richardson, 1937)) $=0.80$, attitude and practice $($ Cronbach's alpha coefficient $($ Cronbach, 1970) $)=0.82$ and 0.79 , respectively.

Evaluation of knowledge level was analyzed according to Bloom (1971), answer correct=1, incorrect=0, and interpreted to high level; 11-15 points, moderate level; 6-10 points, 0-5 points; low level. Evaluation of attitude level was analyzed according to Likert (1977) with 3 choice (agree, not sure, dis-agree): positive question $=3,2,1$, negative question $=1,2,3$, and interpreted to good level; $48-60$ points, fair level; $36-47$ points, and poor level; 0-35 points. Evaluation of practical level was analyzed according to Best (1993) with 3 choice (frequently, sometimes, never): positive question=3,2,1, negative question $=1,2,3$, and interpreted to good level; 3645 points, fair level; $27-35$ points, poor level; 0-26 points. Descriptive statistics were used included frequencies, percentage, mean, and standard deviation.

\section{Results}

The majorities of participants were female (58.3\%), age group between $21-30$ years old $(42.5 \%)$, primary school (59.9\%), agriculture (38.1\%), and married (80.9\%), respectively (Table 1 ).

Past histories regarding liver fluke prevention and control were analyzed and found that $88.3 \%$ of participant had a history with raw fish consumption. In addition, $98.6 \%$ of participant had no stool examination of liver fluke. $4.6 \%$ of participants had anti-parasites used. Meanwhile, $87.5 \%$ of relative family had frequently raw fish consumption.

$87.2 \%$ of participant had perceived liver fluke

Table 2. Health Behavior of Participants Regarding Liver Fluke

\begin{tabular}{lcccc}
\hline Behavior & No of participant & $\%$ & Mean & SD \\
\hline Knowledge & 367 & 100 & 10.9 & 0.5 \\
Low & 15 & 4.1 & 3.1 & 1.2 \\
Moderate & 349 & 95.1 & 10.8 & 1.2 \\
High & 3 & 0.8 & 13.2 & 0.7 \\
Attitude & 367 & 100 & 45.7 & 9.7 \\
Poor & 0 & 0.0 & 0 & 0.0 \\
Fair & 347 & 94.5 & 45.5 & 5.3 \\
Good & 20 & 5.5 & 49.6 & 5.7 \\
Practice & 367 & 100.0 & 30.6 & 10.5 \\
Poor & 92 & 25.1 & 20.6 & 9.6 \\
Fair & 175 & 47.7 & 30.1 & 10.5 \\
Good & 100 & 27.2 & 40.2 & 4.1 \\
\hline
\end{tabular}


prevention and control and identified to messenger; head villages $(50.7 \%)$, village health volunteers $(35.1 \%)$, nurse $(13.1 \%)$, and neighbor $(1.1 \%)$, and medias; television $(45.0 \%)$, village newstation $(43.6 \%)$, poster $(6.5 \%)$, and newspaper $(4.9 \%)$, respectively.

The mean scored of knowledge regarding liver fluke life cycle, transmission, severities, treatment, prevention and control $=10.9(\mathrm{SD}=0.5)$, most of them had a moderate level, $95.1 \%$. The mean scored of attitude regarding liver fluke prevention and control $=45.7(\mathrm{SD}=9.7)$, and practice $=30.6(\mathrm{SD}=10.5)$. The majorities of them had a moderate level of attitude and practice, $94.5 \%$ and 47.7 , respectively (Table 2).

\section{Discussion}

Opisthorchiasis is associated to cholangiocarcinoma that found frequently in northeast and north regions of Thailand (IARC, 1994; kaewpitoon et al., 2008; Sripa et al., 2010; Sithithaworn et al., 2012; Wongsaroj et al., 2014; Kaewpitoon et al., 2015e). Improvement of health behavior regarding liver fluke prevention and control is need required. Here we investigated the behavior of rural people and found that the majorities of participants was age between 21-30 years old. The recent result is surprised that previous reported and indicated normally participants were 30-69 years of age (Chaiputcha et al., 2015; Kompor et al., 2016). Participants are female more than male, these is similar to previous study. Kompr et al (2016) reported the health intervention of liver fluke prevention and contrl in the rural communities of Nakhon Ratchasima, Thailand. The majorities of participants were female, age group 46-55 years old, primary school, marriage, and agriculture. Past histories regarding liver fluke prevention and control found frequently with raw fish consumption and had no stool examination of liver fluke, anti-parasites used. In addition, $87.5 \%$ of relative family had frequently raw fish consumption. Saengsawang et al (2016) reported that reinfection by $O$. viverrini after Treatment with praziquantel. The results of a multiple logistic regression analysis showed that the only factor found to be associated with reinfection was past use of praziquantel. Therefore, young people, primary school, agriculture, and past use of praziquantel are needed urgent required active surveillance including stool examination and health behavioral modification.

Head villages, village health volunteers, television, and village newstation were the main sources for disease information. Improvement of corrected knowledge of head village and village health volunteers about liver fluke disease is need required to prevention and control disease in their communities. Previous reported television is the main source of information (Kaewpitoon et al., in press). Lesson from other investigators have been reported. Promthet et al (2015) recommended that health education and communication for opisthorchiasis prevention in the population: community groups or organizations should be actively encouraged to participate in activity management, using existing cultural and communication media in the community, for example, Mo-lum (northeastern-style singers), public health volunteers in the villages, and community leaders. The successful community-based health education and communication programmes, implemented by teachers and volunteers (Sota et al., 2011; Duangsong et al., 2013). Lawa meodel, the communitybased control model for opisthorchiasis in the Lawa Lake region of Khon Kaen province, Thailand. Encouraged by the largely positive reception from target communities, including community members voluntarily assisting with these activities. They decided to scale-up surveillance and to incorporate a more comprehensive education component than previously offered, targeting schools as well as the general public. By 2012, this program had developed into a district-wide initiative covering 11 villages consisting of a range of activities. Also, by this time they had clearly recognized the parallels of $O$. viverrini control needs and challenges with that of other vector borne and zoonotic diseases for which ecosystem approaches and integrated management were being advocated. The infection rate in the more than 10 villages surrounding the Lake has declined to approximate one third of the average of $50 \%$ as estimated by a baseline survey. Strikingly, the Cyprinoid fish species in the Lake, which are the intermediate host, now showed less than $1 \%$ prevalence compared to a maximum of $70 \%$ at baseline. Lessons learned in developing an integrative control program using a community-based, ecosystem approach, and scaling-up regionally based on members, village health volunteers, village leaders, and public health officers, and members of sub-district administrative organization (Sripa et al., 2015). In addition, Liver fluke prevention and control in the northeast of Thailand through action research was indicated that village member, leaders, village health volunteers, and members of sub-district administrative organization to enhance people's potential to prevent and control liver fluke infection (Wongba et al., 2011).

Recent results found that knowledge, attitude, and practice had a moderate level regarding liver fluke prevention and control. Previously studied indicated that knowledge, attitude, and practice related to liver fluke infection in rural communities (Kaewpitoon et al., 2007). In addition, re-examination in Nakhon Ratchasima province has been reported and found that $O$. viverrini infection is still problem in rural communities (Kaewpitoon et al., 2016a; 2016c). Previous study indicates that people in rural communities are still low to moderate level of knowledge, attitude and practice regarding liver fluke disease. However, their behavioral risk could be improved through health education program (Kompor et al., 2016). Furthermore, inadequate knowledge, misbeliefs, and social and cultural mores were important factors leading to the maintenance of risk behaviors. Moreover, unhygienic defecation and insufficient diagnosis and treatment were found to facilitate $O$. viverrini transmission. Consumption of chopped raw fish salad and Koi pla were independently associated with $O$. viverrini infection (Suwannahitatorn et al., 2013). Therefore, health education is need required in the moderate level, meanwhile health behavior change is urgently in the low level of behavior regarding liver fluke prevention and control.

In conclusion, the behavioral rate of liver fluke of 
participants was relatively moderate level in knowledge, attitude, and practice. Therefore, health education and modification are need required in this communities including stool examination for further active liver fluke screening.

\section{Acknowledgements}

This work was supported by Suranaree University of Technology (SUT) and by Office of the Higher Education Commission under NRU Project of Thailand.

\section{References}

Best JW (1993). Research in education. boston, MA: Allyn and Bacon, 247.

Bloom BS, Hastings JT, Madaus G (1971). Handbook on formative and summative evaluation of student learning. New York: McGraw-Hill.

Chaiputcha K, Promthet S, Bradshaw P (2015). Prevalence and Risk Factors for Infection by Opisthorchis viverrini in an Urban Area of Mahasarakham Province, Northeast Thailand. Asian Pac J Cancer Prev, 16, 4173-6.

Cronbach LJ. (1970). Essential of Psychological Testing. 3rd ed. New York : Harpcr and Row, 161.

Duangsong R, Promthet S, Thaewnongiew K (2013). Development of a community-based approach to opisthorchiasis control. Asian Pac J Cancer Prev, 14, 7039-43.

Green A, Uttaravichien T, Bhudhisawasdi V, et al (1991). Cholangiocarcinoma in northeast Thailand. A hospital-based study. Trop Geogr Med, 43, 193-8.

IARC (1994). Infection with liver flukes (Opisthorchis viverrini, Opisthorchis felineus and Clonorchis sinensis). IARC Monogr Eval Carcinog Risks of Hum, 61, 121-75.

Kaewpitoon N, Kaewpitoon SJ, Pengsaa P, et al (2007). Knowledge, attitude and practice related to liver fluke infection in northeast Thailand. World J Gastroenterol, 13, 1837-40.

Kaewpitoon N, Kaewpitoon SJ, Pengsaa P, et al (2008). Opisthorchis viverrini: the carcinogenic human liver fluke. World J Gastroenterol, 14, 666-74.

Kaewpitoon N, Kaewpitoon SJ, Pengsaa P(2008). Opisthorchiasis in Thailand: review and current status. World J Gastroenterol, 14, 2297-302.

Kaewpitoon N, Kootanavanichpong N, Kompor P, et al (2015). Review and current status of Opisthorchis viverrini infection at the community level in Thailand. Asian Pac J Cancer Prev, 16, 6825-30

Kaewpitoon SJ, Kaewpitoon N, Rujirakul R, et al (2016). Re-Examination of Opisthorchis viverrini in Nakhon Ratchasima province, northeastern Thailand, indicates continued needs for health intervention. Asian Pac J Cancer Prev, 17, 231-4.

Kaewpitoon SJ, Kaewpitoon N, Rujirakul R, et al (2016). Detection of the carcinogenic liver fluke Opisthorchis viverrini using a mini parasep SF faecal parasite concentrator. Asian Pac J Cancer Prev, 17, 373-6.

Kaewpitoon SJ, Kaewpitoon N, Rujirakul R, et al (2016). Nurse and television effecting behavioral improvement regarding liver fluke in Nakhon Ratchasima Province, Thailand. Asian Pac J Cancer Prev, in press

Kaewpitoon SJ, Rujirakul R, Kaewpitoon N (2012). Prevalence of Opisthorchis viverrini infection in Nakhon Ratchasima province, Northeast Thailand. Asian Pac J Cancer Prev, 13, 5245-9.

Kompor P, Muang Karn R, Norkaew J, et al (2016). Population- based intervention for liver fluke prevention and control in Meuang Yang District, Nakhon Ratchasima Province, Thailand. Asian Pac J Cancer Prev, 17, 685-9.

Krejcie RV, Morgan EW (1970). Determining Sample Size for Research Activities. J Edu Psychol Measure, 10, 308.

Kuder GF, Richardson MW. (1937). The theory of the estimation of test reliability. Psychometrika, 2, 151-60.

Likert R (1932). A technique for the measurement of attitudes, Arc Psychol, 140, 44-53

Promthet P, Kessomboon P, Promthet S (2015). Communitybased health education and communication model development for opisthorchiasis prevention in a high risk area, khon kaen province, Thailand. Asian Pac J Cancer Prev, 16, 7789-94.

Saengsawang P, Promthet S, Bradshaw P (2016). Reinfection by Opisthorchis viverrini after Treatment with Praziquantel. Asian Pac J Cancer Prev, 17, 857-62.

Shin HR, Oh JK, Masuyer E, et al (2010). Epidemiology of cholangiocarcinoma: an update focusing on risk factors. Cancer Sci, 101, 579-85.

Sithithaworn P, Andrews RH, Nguyen VD, et al (2012). The current status of opisthorchiasis and clonorchiasis in the Mekong Basin. Parasitol International, 61, 10-6.

Sota C, Sithithaworn P, Duangsong R, et al (2011). The effectiveness of health education program for liver fluke preventing behavior by using hand book and ved in primary school students. Social Sciences, 6, 136-40.

Sripa B, Brindley PJ, Mulvenna J, et al (2012). The tumorigenic liver fluke Opisthorchis viverrini-multiple pathways to cancer. Trends Parasitol, 28, 395-407.

Sripa B, Kaewkes S, Intapan PM, et al (2010). Food-borne trematodiases in Southeast Asia epidemiology, pathology, clinical manifestation and control. Adv Parasitol, 72, 305-50.

Sripa B, Kaewkes S, Sithithaworn P, et al (2007). Liver fluke induces cholangiocarcinoma. PLoS Med, 4, 201.

Sripa B, Tangkawattana S, Laha T, et al (2015). Toward integrated opisthorchiasis control in northeast Thailand: the Lawa project. Acta Trop, 141, 361-7.

Suwannahitatorn P, Klomjit S, Naaglor T, et al (2013). A follow-up study of Opisthorchis viverrini infection after the implementation of control program in a rural community, central Thailand. Parasit Vectors, 6, 188.

Thamavit W, Bhamarapravati N, Sahaphong S, et al (1978). Effects of dimethylnitrosamine on induction of cholangiocarcinoma in Opisthorchis viverrini-infected Syrian golden hamsters. Cancer Res, 38, 4634-9.

Wongba N, Thaewnongiew K, Phathee K et al (2011). Liver fluke prevention and control in the northeast of Thailand through action research. Asian Pac J Cancer Prev, 12, 1367-70.

Wongsaroj T, Nithikathkul C, Rojkitikul W, et al (2014). National survey of helminthiasis in Thailand. Asian Biomedicine, $\mathbf{8}$, 779-83. 